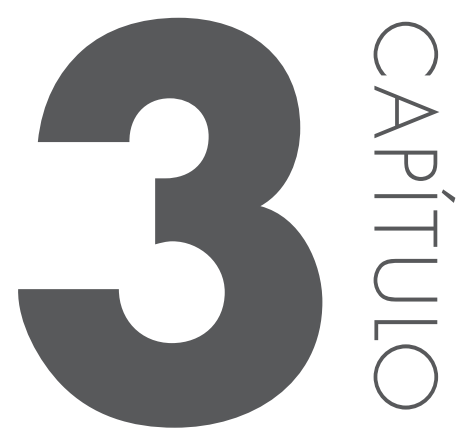

\title{
IDENTIFICAC̣ÃO DE COMPOSTOS ORGÂNICOS VOLÁTEIS NA CIDADE DE CATALÃO-GO EM UM MÊS DE INVERNO
}

Santos, Rafaela Souza ${ }^{*}$; Romualdo, Lincoln Lucílio ${ }^{1}$

'Programa de Pós-Graduação em Química. Departamento de Química. Universidade Federal de Goiás - Regional Catalão. Av. Dr Lamartine P. de Avelar, 1120. Setor Universitário, 75704-020. Catalão-GO

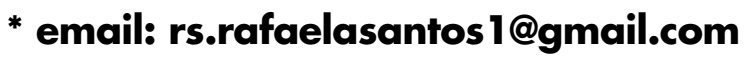


Resumo: A atmosfera está repleta de constituintes que variam em tamanho, composição, fontes de lançamento e estado físico, podendo ser sólidos, líquidos ou gasosos. A classe de constituintes gasosos inclui os compostos orgânicos voláteis (COVs). Os COVs são uma importante classe de compostos que são lançados na atmosfera por fontes naturais e antrópicas. Dentre as fontes naturais destacam-se atividades vulcânicas, atividades metabólicas de espécies vegetais e decomposição de animais e vegetais. Atividades industriais e inerentes o refinamento de petróleo, uso de solventes, atividades relacionadas a agricultura, aterros de resíduos e combustão em fontes móveis e estacionárias estão entre as maiores fontes antrópicas de lançamento desses polventes na atmosfera. A utilização da técnica de SPME, que se baseia na adsorção de compostos de acordo com suas propriedades de polaridade, como ferramenta de amostragem e da cromatografia gasosa acoplada a espectrometria de massas (CG / EM) como ferramenta de análise, tem ganhado destaque nas pesquisas com COVs. O presente trabalho visa identificar os principais COVs presentes no ar na cidade de Catalão-GO utilizando as referidas técnicas de amostragem e análise. Os compostos identificados foram divididos em cinco classes: hidrocarbonetos e derivados, ácidos orgânicos e derivados, compostos sulfurados, compostos nitrogenados e álcoois, aldeídos e derivados. Os resultados apontam para a combustão em veículos automotores como sendo a principal fonte de emissão desses compostos para a atmosfera durante o período em que as amostragens foram realizadas.

\section{Palavras-chave: Compostos orgânicos voláteis; SPME; fontes de emissão de COVs}




\section{Compostos Orgânicos Voláteis}

A atmosfera encontra-se repleta de compostos nos estados sólido, líquido e gasoso variam em tamanho, composição, morfologia e fontes de emissão. Dentre os componentes no estado gasoso estão os compostos orgânicos voláteis (COV).

Apesar de não haver um acordo sobre a definição de COVs, o termo é frequentemente usado para se referir a solventes orgânicos. Nos Estados Unidos, por exemplo, COVs são todos os compostos orgânicos que contribuem para a formação do ozônio fotoquímico. Muitas definições gerais são baseadas nas propriedades físico-químicas dos compostos, como estrutura química, ponto de ebulição e pressão de vapor (DEWULF et al, 2002). 
Rigorosamente falando, o termo COV refere-se aos compostos orgânicos presentes na atmosfera como gases, mesmo que em condições normais de temperatura e pressão sejam encontrados nos estados sólido ou líquido. Sendo assim, estes compostos possuem, a $20{ }^{\circ} \mathrm{C}$, pressão de vapor compreendida entre 1 e $700 \mathrm{mmHg}$. Mas de uma forma geral pode-se considerar como COV quaisquer compostos orgânicos presentes na atmosfera excluindo o carbono elementar, o monóxido de carbono e o dióxido de carbono (SOUSA, 2002).

Estes compostos podem ser lançados na atmosfera por fontes naturais e antrópicas. Dentre as fontes naturais destacam-se as erupções vulcânicas e a atividade metabólica de algumas espécies vegetais. Como fontes antrópicas podem ser destacadas a exaustão de veículos, o uso de solventes, emissões fugitivas e descargas em processos industriais, refino de óleo, armazenagem e distribuição de petróleo e gás natural, aterros de resíduos, agricultura, entre outras (SOUSA, 2002). Ainda segundo Jones (1999), cerca de 52\% das emissões dos COVs estão relacionados com a indústria. O Quadro 1 traz uma lista com os principais COVs encontrados em ambientes fechados.

Quadro 1 - Fontes comuns de compostos orgânicos voláteis no ar

\begin{tabular}{|l|l}
\hline \multicolumn{1}{|c|}{ Fontes } & \multicolumn{1}{|c}{ Exemplos de contaminantes típicos } \\
\hline \multirow{3}{*}{$\begin{array}{l}\text { Produtos comerciais e de } \\
\text { consumo }\end{array}$} & $\begin{array}{l}\text { Hidrocarbonetos alifáticos (n-decano, alcanos } \\
\text { ramificados), hidrocarbonetos aromáticos (tolueno, } \\
\text { xilenos), hidrocarbonetos halogenados (diclorometano), } \\
\text { álcoois, cetonas (acetona, metil etil cetona), aldeídos } \\
\text { (formaldeído), ésteres (alquil etóxilatos), éteres (éter } \\
\text { glicol), terpenos (limoneno, alfa-pireno). }\end{array}$
\end{tabular}

\begin{tabular}{|l|l}
\hline \multirow{3}{*}{ Tintas e suprimentos associados } & $\begin{array}{l}\text { Hidrocarbonetos alifáticos (n-hexano, n-heptano), } \\
\text { hidrocarbonetos aromáticos (tolueno), hidrocarbonetos } \\
\text { halogenados (diclorometano, 1,2-dicloropropano), } \\
\text { álcoois, cetonas (metil etil cetona), ésteres (etil acetato), } \\
\text { éteres (metil éter, éter dietílico, butil éter). }\end{array}$ \\
\hline Adesivos & $\begin{array}{l}\text { Hidrocarbonetos alifáticos (hexano, heptano), } \\
\text { hidrocarbonetos aromáticos, hidrocarbonetos } \\
\text { halogenados, álcoois, aminas, cetonas (acetona, metil } \\
\text { etil cetona), ésteres (vinil acetato), éteres. }\end{array}$ \\
\hline Acessórios e vestimenta & $\begin{array}{l}\text { Hidrocarbonetos aromáticos (estireno, aromáticos } \\
\text { bromados), hidrocarbonetos halogenados (cloreto de } \\
\text { vinila), aldeídos (formaldeído), éteres, ésteres. }\end{array}$ \\
\hline Materiais de construção & $\begin{array}{l}\text { Hidrocarbonetos alifáticos (n-decano, n-dodecano), } \\
\text { hidrocarbonetos aromáticos (tolueno, estireno, } \\
\text { etilbenzeno), hidrocarbonetos halogenados (cloreto de } \\
\text { vinila), aldeídos (formaldeído), cetonas (acetona, } \\
\text { butanona), ésteres (uretano, etilacetato). }\end{array}$ \\
\hline Sistemas de combustão & $\begin{array}{l}\text { Hidrocarbonetos alifáticos (propano, butano, isobutano), } \\
\text { aldeídos (acetaldeído, acroleína). }\end{array}$ \\
\hline
\end{tabular}


Além dos gases predominantes na composição da atmosfera (nitrogênio - 78\% e oxigênio - $21 \%$, as principais espécies presentes no ar não-polvído são: óxidos inorgânicos $\left(\mathrm{CO}, \mathrm{CO}_{2}, \mathrm{NO}_{2}, \mathrm{SO}_{2}\right)$, oxidantes $\left(\mathrm{O}_{3}, \mathrm{H}_{2} \mathrm{O}_{2}, \mathrm{OH}, \mathrm{O}_{2} \mathrm{H}, \mathrm{NO}_{3}\right)$, redutores $\left(\mathrm{CO}, \mathrm{SO}_{2}, \mathrm{H}_{2} \mathrm{~S}\right)$, orgânicos (alcanos, alcenos, arilas, carbonilas, nitratos orgânicos, etc.), espécies fotoquimicamente ativas $\left(\mathrm{NO}_{2}\right.$, formaldeído, entre outros), ácidos $\left(\mathrm{H}_{2} \mathrm{SO}_{4}\right)$, bases $\left(\mathrm{NH}_{3}\right)$, sais $\left(\mathrm{NH}_{4} \mathrm{HSO}_{4}\right.$ ) e espécies reativas (como os radicais livres $\mathrm{O}^{\bullet}$ e $\mathrm{OH}^{*}$ ). Também estão presentes aerossóis (sólidos e líquidos) que geralmente atuam como meio para a reação entre as espécies químicas (SCHRIMER e QUADROS, 2010).

Por ser muito abrangente, o termo COV possui algumas variações como é o caso dos compostos orgânicos voláteis de enxofre e compostos orgânicos voláteis biogênicos. Os compostos orgânicos voláteis de enxofre referem-se a COVs contendo um átomo de enxofre e incluem principalmente os compostos de enxofre reduzidos como metilmercaptanas, dimetilssulfeto, dimetildissulfeto, sulfeto de carbonila e dissulfeto de carbono. Estes compostos tem atraído atenção devido aos seus efeitos a saúde e seu papel na química atmosférica, além de possuírem odor desagradável e limiares sensoriais muito baixos, podendo ser de até $6 \mu \mathrm{g} \cdot \mathrm{m}^{-3}$ (WU et al, 2010).

O termo compostos orgânicos voláteis biogênicos refere-se aos compostos orgânicos emitidos a partir de uma fonte natural, como é o caso dos gases de dióxido de enxofre provenientes de erupções vulcânicas emitidos em quantidades sempre superiores àqueles oriundos de termelétricas ou qualquer outra atividade humana (SCHRIMER e QUADROS, 2010).

A exposição a esses compostos pode gerar efeitos a saúde agudos e crônicos. Pessoas com asma e problemas respiratórios anteriores são mais suscetíveis a apresentarem agravamento de suas doenças quando expostas a baixas concentrações de COVs. A exposição pode também levar a irritações nos olhos e trato respiratório, causam ainda reações de sensibilização envolvendo os olhos, pele e pulmões. Em altas concentrações os COVs são narcóticos e podem atingir o sistema nervoso central e em concentrações extremas alguns COVs podem comprometer funções neurocomportamentais. O tolueno, por exemplo, em concentrações acima de $188 \mu \mathrm{g} \cdot \mathrm{m}^{-3}$ causa sintomas de letargia, vertigens e confusão, podendo progredir para um estado de coma, convulsões e possivelmente morte em níveis maiores que $35000 \mu \mathrm{g} \cdot \mathrm{m}^{-3}$ (JONES, 1999).

Todas as áreas de pesquisa que lidam com os COVs tem obtido êxito nas análises por cromatografia gasosa (CG). A análise de COVs em matriz sólida, líquida ou gasosa geralmente se inicia com uma fase de pré-concentração, como a utilização de sólidos adsorventes, pré-concentração criogênica, dispositivos com membranas, extração por solvente, headspace estático e dinâmico, micro-extração por fase sólida (SPME, do inglês solid phase micro-extraction), e técnicas de destilação e sublimação. É importante ressaltar que as técnicas de pré-concentração levam em conta a polaridade dos analitos alvo, especialmente técnicas que utilizam sólidos adsorventes (DEWULF et al, 2002). 


\section{Metodologia}

\subsection{Amostragem}

A identificação dos constituintes do ar foi realizada pela técnica de microextração por fase sólida (SPME). Para tanto, utilizou-se três fibras de adsorção com diferentes composições e porosidade a fim de capturar o maior número possível de constituintes voláteis presentes no ar.

As fibras foram deixadas em local aberto em uma área próxima a uma avenida onde o trânsito é intenso nos horários de pico. As amostragens foram feitas durante todo o mês de julho duas vezes na semana, sendo que em uma semana ocorria no período da noite e na semana seguinte durante $o$ dia.

\section{As fibras utilizadas possuem as seguintes propriedades:}

- Fibra branca: revestimento de poliacrilato, poros de $85 \mu \mathrm{m}$, polar;

- Fibra preta: revestimento de Carboxeno Polidimetilsiloxano (CAR/PDMS), poros de $75 \mu \mathrm{m}$, bipolar;

- Fibra vermelha: revestimento de PDMS, poros de 100 pm, não-polar.

\subsection{Análise}

A dessorção térmica e análise dos compostos voláteis orgânicos adsorvidos nas fibras foram feitas em um sistema de cromatografia gasosa (CG - modelo 7820A, Agilent Technologies) acoplada a um detector de espectrometria de massas (EM - modelo 5975 Series MSD, Agilent Technologies).

A operação do sistema foi conduzida de acordo com as seguintes rampas de temperatura: $50{ }^{\circ} \mathrm{C}$ por $3 \mathrm{~min}, 10^{\circ} \mathrm{C} / \mathrm{min}$ até $100^{\circ} \mathrm{C}, 15^{\circ} \mathrm{C} / \mathrm{min}$ até $200{ }^{\circ} \mathrm{C}, 20^{\circ} \mathrm{C} / \mathrm{min}$ até $240^{\circ} \mathrm{C}$. O fluxo do gás carreador foi operado a $1,0 \mathrm{~mL} / \mathrm{min}$. A temperatura do injetor foi mantida a $250^{\circ} \mathrm{C}$ em todas as análises.

A identificação dos possíveis compostos foi feita por comparação com os espectros contidos na base de dados da biblioteca NIST / MS (Nacional Institute of Standards and Technology / Mass Spectral).

\section{Resultados e discussão}

Os constituintes gasosos do ar encontrados nas amostragens realizadas de 01/07/2014 a 31/07/2014, conforme o protocolo citado anteriormente, foram divididos em cinco grupos (compostos sulfurados; compostos com anéis nitrogenados; hidrocarbonetos 
e derivados; ácidos orgânicos e derivados; e álcoois, aldeídos derivados) e estão dispostos nas Tabelas 1 a 3, a seguir.

Tabela 1 - Compostos identificados na fibra vermelha no mês de julho de 2014

\begin{tabular}{c|l}
\hline Classe de compostos & \multicolumn{1}{|c}{ Compostos identificados } \\
\hline \multirow{3}{*}{ Derivados de ácidos orgânicos } & $\begin{array}{l}\text { isobutil éster 2,2,4-trimetil-3-carboxiisopropil ácido } \\
\text { pentanóico }\end{array}$ \\
\cline { 2 - 2 } & $\begin{array}{l}\text { bis(2-metilpropil) éster ácido 1,2- } \\
\text { benzenodicarboxílico }\end{array}$ \\
\hline Hidrocarbonetos e derivados & 6,10,14-trimetil 2-pentadecanona \\
\hline Álcoois, aldeídos e derivados & 2-hexil-1-octanol \\
\hline Compostos sulfurados & 2-hexadecanol \\
\hline Compostos contendo anéis & cloreto de 1-octadecanossulfonil \\
nitrogenados & \\
\hline
\end{tabular}

Tabela 2 - Compostos identificados na fibra branca no mês de julho de 2014

\begin{tabular}{c|l}
\hline Classe de compostos & \multicolumn{1}{|c}{ Compostos identificados } \\
\hline \multirow{2}{*}{ Derivados de ácidos orgânicos } & bis(2-metilpropil)éster ácido 1,2-benzenodicarboxílico \\
\cline { 2 - 2 } & 4-hidróxi ácido butanoico \\
\hline \multirow{2}{*}{ Hidrocarbonetos e derivados } & tetrahidrofurano \\
\cline { 2 - 2 } & 2,4-diisocianato-1-metil benzeno \\
\cline { 2 - 2 } Cenzofenona \\
\hline \multirow{2}{*}{$\begin{array}{c}\text { Compostos sulfurados } \\
\text { Compostos contendo anéis } \\
\text { nitrogenados }\end{array}$} & $\begin{array}{l}\text { 1,1'-(4-metil-1,3-fenileno)bis\{3-]5-(p-tolil)-1,3,4- } \\
\text { tiadiazol-2-il]uréia\} }\end{array}$ \\
\cline { 2 - 2 } & 4-(1-pirrolidinil) piridina \\
\hline
\end{tabular}


Tabela 3: Compostos identificados na fibra preta no mês de julho de 2014

\begin{tabular}{|c|c|}
\hline Classe de compostos & Compostos identificados \\
\hline \multirow[t]{7}{*}{ Derivados de ácidos orgânicos } & fenilmetil éster ácido hidrazinocarboxílico \\
\hline & metil éster ácido 9-octadecen-12-inóico \\
\hline & metil éster ácido 12,15-octadecadiinóico \\
\hline & metil éster 2-metóxi ácido tricosanóico \\
\hline & ácido biciclo[3.3.1]non-6-eno-3-carboxílico \\
\hline & fenilmetil éster ácido hidrazinocarboxílico \\
\hline & (E) metil éster ácido 10-heptadecen-8-inóico \\
\hline \multirow[t]{7}{*}{ Derivados de ácidos orgânicos } & $\begin{array}{l}\text { isobutil éster 2,2,4-trimetil-3-carboxiisopropil ácido } \\
\text { pentanóico }\end{array}$ \\
\hline & metil éster ácido 10,13-octadecadiinóico \\
\hline & ácido pterin-6-carboxílico \\
\hline & ácido 17-octadecinóico \\
\hline & (E) metil éster ácido 10-heptadecen-8-inóico \\
\hline & (Z) 2-(9-octadecenilóxi)etil éster ácido esteárico \\
\hline & N-metil butil éster ácido antranílico \\
\hline \multirow[t]{15}{*}{ Hidrocarbonetos e derivados } & 3-(prop-2-enoiloxi)dodecano \\
\hline & 2-propenilideno ciclobuteno \\
\hline & p-xileno \\
\hline & 1-etil-3-metil benzeno \\
\hline & 1,3-dicloro benzeno \\
\hline & N-trifluoroacetil 1-aminononadecano \\
\hline & 3-trifluoroacetoxipentadecano \\
\hline & Z,Z,Z-1,4,6,9-nonadecatetraeno \\
\hline & 1,2-15,16-diepóxihexadecano \\
\hline & benzeno \\
\hline & 1,3,5-cicloheptatrieno \\
\hline & n-hexano \\
\hline & 1,4-dihidroxi-p-ment-2-eno \\
\hline & 1-(etenilóxi) octadecano \\
\hline & $\beta$-copaeno \\
\hline
\end{tabular}


Tabela 3: Compostos identificados na fibra preta no mês de julho de 2014 (continuação)

\begin{tabular}{|c|c|}
\hline Classe de Compostos & Compostos Identificados \\
\hline \multirow[t]{10}{*}{ Hidrocarbonetos e derivados } & 2,5-di-tert-butil-1,4-benzoquinona \\
\hline & clorometil octil éter \\
\hline & fluoreto de octanoil \\
\hline & 4-cloro octano \\
\hline & tolveno \\
\hline & 2-propenilideno ciclobuteno \\
\hline & 4-[bis(p-hidroxifenil)metileno]- \\
\hline & -2,5-ciclohexadien-1-ona \\
\hline & m-fenetil benzonitrila \\
\hline & 2,6-bis(1,1-dimetiletil) 2,5-ciclohexadieno-1,4-diona \\
\hline \multirow[t]{20}{*}{ Álcoois, aldeídos e derivados } & biciclo[2.2.0[hex-1-il metanol \\
\hline & 2-etenil biciclo[2.2.0]hexan-2-ol \\
\hline & octanal \\
\hline & $(1 \alpha, 2 \beta, 5 \alpha)$ 2-metil-5-(1-metiletenil) ciclohexanol \\
\hline & nonanal \\
\hline & 10-metoxitriciclo[4-2.1.1(2,5)]deca-3,7-dien-9-ol \\
\hline & 3,7,11-trimetil 1-dodecanol \\
\hline & 2-hexadecanol \\
\hline & 2,6-bis(1,1-dimetiletil) 1,4-benzenodiol \\
\hline & 1,3-dicloro 2-propanol \\
\hline & 3-benziloxi-2-fluoro-4-metóxi benzaldeído \\
\hline & 2-etenil biciclo[2.1.1] hexan-2-ol \\
\hline & 2-metil-5-(1-metiletenil) ciclohexanol \\
\hline & (Z) 7-hexadecenal \\
\hline & trans-p-menta-1 (7),8-dien-2-ol \\
\hline & decanal \\
\hline & $(3 \beta, 5 \alpha)$ 2-metileno cholestan-3-ol \\
\hline & 4-(2,2-dimetil-6-metilenociclohexil)butanal \\
\hline & 2-metil 1-hexadecanol \\
\hline & 2-octen-1-ol \\
\hline
\end{tabular}


Tabela 3: Compostos identificados na fibra preta no mês de julho de 2014 (continuação)

\begin{tabular}{c|l}
\hline Classe de compostos & \multicolumn{1}{c}{ Compostos Identificados } \\
\hline Álcoois, aldeídos e derivados & 2-etenil biciclo[2.1.1] hexan-2-ol \\
\cline { 2 - 2 } & 1,8-nonadien-3-ol \\
\cline { 2 - 2 } & 3-benzilóxi-2-fluoro-4-metóxi benzaldeído \\
\cline { 2 - 2 } & biciclo[2-2.0]hex-1-il- metanol \\
\cline { 2 - 2 } Compostos sulfurados & 5-metil-1,5-hexadien-3-ol \\
\cline { 2 - 2 } & etenil tert-butil sulfóxido \\
\cline { 2 - 2 } Compostos contendo anéis & $\begin{array}{l}\text { 4-dehidróxi-N-(4,5-metilenodióxi-2- } \\
\text { nitrobenzilideno)tiramina }\end{array}$ \\
\cline { 2 - 2 } nitrogenados & 5-metil-2-fenil 1H-indol \\
\hline
\end{tabular}

A divisão dos compostos em diferentes grupos foi realizada com o intuito de facilitar a discussão a respeito das possíveis fontes de emissão.

A quantidade de compostos identificados em cada fibra varia de acordo com as propriedades de polaridade do material de recobrimento de cada uma. As fibras branca e vermelha por serem polar e não-polar, respectivamente, adsorveram uma menor variedade de compostos. As fibras vermelhas são indicadas basicamente para adsorção de compostos apolares, enquanto as fibras brancas podem ser usadas quando os compostos alvo são medianamente a altamente polares, como fenóis, pesticidas organofosforados, cetonas, álcoois e demais orgânicos voláteis de média a alta polaridade (VALENTE e AUGUSTO, 2000).

A fibra preta é considerada bipolar e portanto é indicada para adsorção de compostos voláteis e não-voláteis de baixa a alta polaridade, o que está de acordo com a maior variedade de compostos identificados nesta fibra.

Em relação as fontes de emissão dos compostos identificados a literatura aponta os processos de combustão de fontes móveis e estacionárias como sendo os maiores contribuintes para o lançamento desses compostos na atmosfera.

Os compostos derivados de ácidos orgânicos podem ser provenientes dos processos de combustão de veículos, em especial de locomotivas. Mas podem também ser formados na atmosfera por reações fotoquímicas entre aldeídos e cetonas com a geração de radicais livres, que por sua vez reagem rapidamente com o oxigênio atmosférico produzindo peróxidos e ácidos orgânicos (PIRES, 2005; SOUZA e CARVALHO, 1997).

Os compostos pertencentes a classe de álcoois, aldeídos e derivados podem ser lançados na atmosfera por fontes naturais e antrópicas. Surgem a partir de processos industriais e de combustão, e queima de vegetação. Podem ainda serem formados na 
atmosfera por reações fotoquímicas de hidrocarbonetos (ANDRADE et al, 2002; PIRES, 2005).

Os hidrocarbonetos por sua vez são emitidos a partir de processos de combustão de fontes estacionárias e veículos automotores, processos industriais e atividade metabólica de algumas espécies vegetais (PIRES, 2005; SOUSA, 2002).

Os compostos sulfurados e nitrogenados possuem como principal fonte de emissão a combustão a partir de veículos automotores. Os óxidos de nitrogênio, em especial, são emitidos por fontes de combustão móveis e estacionárias e exercem papel fundamental na formação do smog fotoquímico. Os compostos contendo enxofre são oriundos da queima de combustíveis fósseis e atividades industriais como refino de petróleo, indústrias de cimento e metalúrgica (MARTINS e ANDRADE, 2002).

\section{Conclusões}

A partir da análise dos resultados em comparação com os dados da literatura é possivel afirmar que durante o mês em que foram realizadas as amostragens a maioria dos compostos identificados pela técnica utilizada são provenientes da combustão em veículos automotores.

Tais resultados acordam com o perfil do local onde as amostragens foram realizadas, próximo a um estacionamento e a uma avenida em que o tráfego é intenso principalmente nos horários de pico.

Apesar das amostragens realizadas não serem representativas do ano uma análise inicial é importante no sentido de definir o melhor caminho a seguir. A fim de traçar o perfil dos compostos presentes no ar na cidade de Catalão-GO de acordo com as estações do ano e os índices pluviométricos em cada mês as amostragens continuarão sendo realizadas seguindo os mesmos protocolos utilizados neste trabalho. 


\title{
Identification of volatile organic compounds in the city of Catalão-GO in a winter month
}

\begin{abstract}
The atmosphere is filled with components that vary in size, composition, sources of release and physical state and may be solid, liquid or gaseous. The class of gaseous constituents include the volatile organic compounds (VOCs). VOCs are an important class of compounds that are emitted into the atmosphere by natural and anthropogenic sources. Among the natural sources include volcanic activity, metabolic activities of plants and decaying animal and vegetable. Industrial activities and associated oil refining, solvent use, agriculture related activities, waste landfills and combustion in mobile and stationary sources are among the largest sources of anthropogenic release of these pollutants into the atmosphere. The use of SPME technique, which is based on the adsorption of compounds according to their polarity properties such as sampling and analysis by gas chromatography-mass spectrometry (GC / MS) has gained prominence in the research with VOCs. This work aims to identify major VOCs present in the air in the city of Catalão-GO using these techniques for sampling and analysis. Compounds identified were divided into five classes: hydrocarbons and derivatives, organic acids and derivatives, sulfur compounds, nitrogen compounds and alcohols, aldehydes and derivatives. The results point to the combustion in motor vehicles as the main source of emission of these compounds into the atmosphere during the period in which the samples were taken.
\end{abstract}

Keywords: volatile organic compounds; SPME; emission source of VOCs

\section{Referências bibliográficas}

ANDRADE, M. V. A. S. et al. Compostos carbonílicos atmosféricos: fontes, reatividade, níveis de concentração e efeitos toxicológicos. Química Nova, v. 25, n. 6b, p.1117-1131,2002.

DEWULF, J.; VAN LAGENHOVE, $H$. Analysis of volatile organic compounds using gas chromatography. Trends in anallytical chemistry. v.21, n. 9-10, p. 637-645, 2002. 
JONES, A. P. Indoor air quality and health. Atmospheric Environment. v. 33, p. 4535-4564, 1999 MARTINS, C. R.; ANDRADE, J. B. Química atmosférica do enxofre (IV): emissões, reações em fase aquosa e impacto ambiental. Química Nova. v. 25, n. 2, p. 259-272, 2002.

PIRES, D. O. Inventário de emissões atmosféricas de fontes estacionárias e sua contribuição para a polvição do ar na região metropolitana do Rio de Janeiro. 2005. 188 f. Dissertação (Mestrado em Ciências) - Universidade Federal do Rio de Janeiro, Rio de Janeiro, 2005.

SCHRIMER, W. N.; QUADROS, M. E. Compostos orgânicos voláteis biogênicos emitidos a partir de vegetação e seu papel no ozônio troposférico urbano. Revista da Sociedade Brasileria de Autorização Urbana, Piracicaba, v. 5, n. 1, p. 25-42, 2010.

SOUSA, K. R. de P. Estudo sobre compostos orgânicos voláteis presentes no ar no município de Paulínia. 2002. 193 f. Dissertação (Mestrado em Engenharia Química) - Faculdade de Engenharia Química, Universidade Estadual de Campinas, Campinas, 2002.

SOUZA, S. R.; CARVALHO, L. R. F. Determinação de ácidos carboxílicos na atmosfera urbana de São Paulo. Uma abordagem analítica e ambiental. Química Nova, v. 20, n. 3, p. 245-251, 1997.

VALENTE, A. L. P.; AUGUSTO, F. Microextração por fase sólida. Química Nova, v. 23, n. 4, p. 523-530, 2000.

WU, T. et al. Emission of volatile organic sulfur compounds (VOSCs) during aerobic decomposition of food wastes. Atmospheric Environment. v. 44, p. 5065-5071, 2010. 